\title{
ARTIGO
}

\section{MODELO OPERACIONAL PARA UMA MICROCERVEJARIA CIGANA ${ }^{1}$}

\author{
Raphael Athos dos Santos ${ }^{2}$ \\ Luciana Emirena dos Santos Carneiro \\ Lucas Maia dos Santos
}

\begin{abstract}
RESUMO
Este artigo tem o objetivo de propor um modelo operacional para empreendedores e administradores do mercado de cervejas artesanais. Um modelo de negócio que tem se tornado muito comum neste mercado crescente é o conhecido como cervejaria cigana. Neste modelo as microcervejarias terceirizam sua produção para diminuir custos e concentrar esforços em outros pontos da cadeia de valor. Através do modelo proposto de uma microcervejaria, este artigo demonstra passo a passo como deve ser a operação de uma cervejaria cigana competitiva. Este modelo foi desenvolvido com base em diversas teorias da administração que orientam o planejamento e execução das atividades, desde a identificação da necessidade de compra de matéria-prima até a distribuição do produto para varejistas. Pontos como as legislações que regulamentam as operações e dados históricos relacionados a produção de cerveja no Brasil e no mundo também são apresentados, além de referências relacionadas ao mercado consumidor e o seu crescimento nos últimos anos.
\end{abstract}

Palavras-chave: Microcervejaria. Administração da produção. Terceirização. Modelo operacional.

\section{INTRODUÇÃO}

O mercado cervejeiro tem faturamento aproximado de 70 bilhões de reais ao ano, que representa 1,6\% do PIB nacional, gera aproximadamente 21 bilhões em impostos e 2,2 milhões de empregos (CERVBRASIL, [2015]).

De acordo com o SEBRAE ([20--]) o segmento de cervejas artesanais representa, no momento, apenas $1 \%$ deste mercado, mas tem apresentado grandes possibilidades de crescimento devido à valorização cada vez maior do produto pelos consumidores. Outro

\footnotetext{
${ }^{1}$ Como citar este artigo: SANTOS, Raphael Athos dos; CARNEIRO, Luciana Emirena dos Santos; SANTOS, Lucas Maia dos. Modelo operacional para cervejaria cigana. ForScience: revista científica do IFMG, Formiga, v. 6, n. 1, e00292, jan./jul. 2018.
}

\footnotetext{
${ }^{2}$ Autor para correspondência: Raphael Athos dos Santos, IFMG - Campus Sabará, e-mail:
} raphaelathos@outlook.com 
indicador de crescimento é a comparação do mercado brasileiro com o externo. De acordo com Delgado (2016) países europeus e os Estados Unidos já passaram por movimentos semelhantes ao que acontece hoje no Brasil, relacionados à microcervejarias. Delgado (2016) nos mostra que hoje nos Estados Unidos as microcervejarias possuem um Market-Share de $11 \%$, o que aponta o tamanho da margem de crescimento do segmento em comparação ao $1 \%$ de Market-Share no mercado brasileiro, apontados pelo SEBRAE ([20--]). Baseando-se nestas informações, o segmento de microcervejarias deverá crescer substancialmente nos próximos anos, o que atrairá a atenção de muitos empreendedores e investidores.

Nesse mercado há um modelo de negócio conhecido como cervejaria cigana, que na definição de Chaves (2016), é uma microcervejaria, que por decisão estratégica não possui fábrica própria e terceiriza etapas da produção. Mas como deve ser a operação da produção desse modelo de negócio, para que uma empresa que opte por ele possa ser competitiva? Esta resposta não foi encontrada em publicações depois de feita uma pesquisa exploratória sobre o tema no site de busca de publicações científicas scholar.com, o que justifica o objetivo deste artigo, que é propor um Modelo Operacional para este modelo de negócio.

O Modelo Operacional é a descrição da organização interna de uma empresa no sentido de sua capacidade de produzir e vender, instalações, equipamentos e deve conter as ações que a empresa está planejando as quais vão influenciar o sistema produtivo, a descrição de todo o processo de fabricação, e caso alguma etapa seja terceirizada, essa terceirização deverá ser descrita, além de descrever o fluxo de produtos da produção até o cliente e os procedimentos de remessa (DORNELAS, 2008; HISRICH; PETERS; SHEPHERD, 2009; ROSA 2013).

O modelo operacional que será proposto tem como principal diferencial, de outros modelos já estudados, ser completamente voltado para microcervejarias ciganas, com foco em uma produção de menor porte, baixos níveis de estoque e atenção especial em relação aos procedimentos em etapas terceirizadas do ciclo produtivo. Chaves (2016) explica que o modelo de negócio das microcervejarias, permite que estas empresas iniciem suas operações com investimento inicial até 10 vezes menor que microcervejarias comuns, o que permite maior acesso de novos empreendedores a este setor da economia. O modelo operacional que será proposto por este artigo vai além do modelo de negócio, com foco na orientação das operações de produção das empresas, para que haja maior qualidade dos produtos, maior resultado econômico e geração de emprego.

Este artigo irá usar o método definido por Andrade (2010) como exploratório, ao levantar dados e informações através de sites, livros e redes sociais que possuam ligação com 
o setor específico de microcervejarias e teorias aplicáveis de administração e logística quanto ao controle da produção.

\section{HISTÓRICO DA PRODUÇÃO DE CERVEJA}

A história da produção da cerveja tem sua cronologia descrita e estabelecida nas civilizações desde 6000 anos Antes de Cristo e estes fatos históricos destacam como a cerveja já era uma bebida produzida e consumida pelos povos que tinham nessa preferência o desafio e a necessidade de se estruturarem enquanto unidade produtiva (HUGHES, 2016; MORADO, 2009).

De acordo com Morado (2009), neste período a produção de cerveja já era uma atividade bem estabelecida e organizada, que provavelmente foi descoberta por acaso muito antes na história, quando os povos desenvolveram as primeiras técnicas para cultivo e armazenamento de grãos.

\footnotetext{
É bastante provável que, em alguma ocasião, um grupo de agricultores tenha armazenado a colheita em vasos, para uso posterior. Uma chuva eventual tratou de umedecer a porção que, em seguida, deve ter sido colocado para secar. A etapa seguinte da preparação da cerveja consiste em fazer uma sopa desses grãos umedecidos e secos (malte verde). Se essa sopa for abandonada, será atacada por micro-organismos presentes na atmosfera, o que dará início a fermentação. A fermentação dessa sopa produz álcool a partir do açúcar. Eis a cerveja (MORADO, 2009, p. 22).
}

Hughes (2016) descreve outros importantes fatos históricos, como no ano 822 d.C, que está a primeira ligação documentada entre lúpulo e cerveja, a fundação da primeira cervejaria comercial no ano 1040, o registro da primeira cerveja produzida com lúpulo na Inglaterra em 1412, a promulgação da lei de pureza alemã em 1516, o nascimento do Oktoberfest em Munique no ano de 1810, a produção da primeira lager dourada em Pilsen no ano 1842, o descobrimento da atuação da levedura na cerveja em 1857, o início da lei seca nos E.U.A em 1919 e a partir de 1990 o renascimento do interesse na cerveja artesanal pelas pessoas em diversos países do mundo.

Quanto à história da produção de cerveja no Brasil, Morado (2009) conta que a bebida chegou ao país pela primeira vez no século 12 , junto com os holandeses, e até o final do século XIX era produzida artesanalmente, com muita dificuldade por causa da falta de ingredientes e por causa das altas temperaturas tropicais. Morado (2009) completa que por volta de 1850, algumas cervejarias artesanais atingiram escalas industriais, como a Cia. 
Cervejaria Brahma e a Cia. Antarctica Paulista ou a Imperial Fábrica de Cerveja Nacional, que em 1898 passaria a se chamar Cervejaria Bohemia. Morado (2009) ainda ressalta que a partir de 1980 a cultura cervejeira no Brasil se transforma, diversas microcervejarias são abertas no país, modernas choperias alteram o até então conhecido boteco e as mulheres se incorporam ao mercado consumidor, antes predominantemente masculino.

Alinhado à solidificação das indústrias cervejeiras no Brasil e no mundo e ao crescimento e diversificação do público consumidor, Hughes (2016) explica que o mercado global ainda é dominado pelas grandes cervejarias, mas que nos últimos anos o número de cervejarias artesanais tem crescido, afirmação ratificada pelo SEBRAE ([20--]) que declara que o movimento de consumo da cerveja artesanal chegou ao Brasil e chegou para ficar.

\section{ADMINISTRAÇÃO DA PRODUÇÃO}

O Modelo Operacional proposto é para uma produção de 4.000 litros de cerveja em garrafas de $600 \mathrm{ml}$, ilustrada na Tabela 1, divididos igualmente entre as receitas Belgian Ale, IPA, Pilsen Premium e Stout. A escolha do volume de produção foi feito por representar um menor investimento inicial. De qualquer forma o volume de produção pode ser adaptado de acordo com as necessidades e capacidade de investimento. A escolha das receitas foi com o objetivo de obter economia de escopo, caracterizada por Szwacfiter e Dalcol (1997) como uma economia advinda da produção de produtos diversos, mas que utilizam em grande parte as mesmas matérias-primas e componentes intermediários.

Tabela 1 - Produção Mensal

\begin{tabular}{lll}
\hline Receita & Produção/Litros & Garrafas 600 ml \\
\hline Belgian Ale & 1000 & 1666 \\
IPA & 1000 & 1666 \\
Pilsen Premium & 1000 & 1666 \\
Stout & 1000 & 1666 \\
\hline
\end{tabular}

De acordo com Morado (2009), no passado as cervejarias utilizavam a força da gravidade na produção, necessitando assim que o layout das fábricas fosse projetado de forma que a produção começava nos níveis mais altos e terminava nos níveis mais baixos, diferente de hoje, onde as cervejarias possuem tecnologia de transporte e bombeamento. Morado (2009) completa que a produção de cerveja consiste basicamente em moer o malte de cevada, 
colocar em infusão, coar, ferver com lúpulo, coar, acrescentar a levedura e deixar o líquido fermentar e depois deixar em repouso, tudo isso com controle rigoroso de temperatura, tempo, pressão e PH. As etapas do modelo operacional proposto por este artigo são ilustradas na figura 2 .

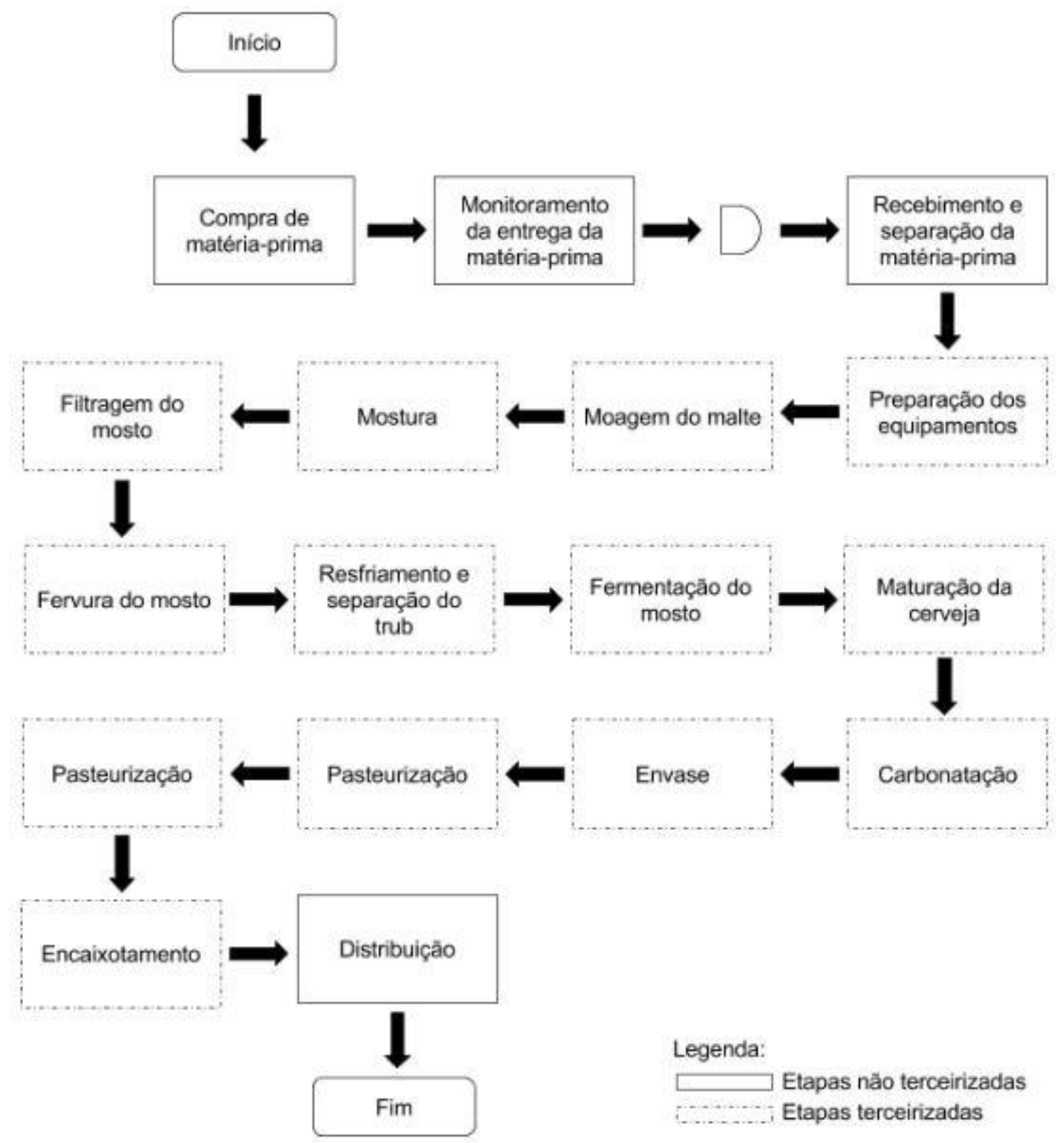

Figura 1 - Fluxograma do processo produtivo da empresa

A Figura 1 apresenta etapa a etapa do processo produtivo, que serão detalhadas nos trechos a seguir. O uso de fluxograma é uma forma de ilustrar o processo possibilitando que ele possa ser visualizado como um todo. Parte deste processo será realizado pela própria cervejaria, mas por decisão estratégica algumas etapas serão terceirizadas.

Chaves (2016) explica que algumas microcervejarias, conhecidas como cervejarias por contrato ou cervejarias ciganas, por não possuírem equipamentos, contratam outras cervejarias para produzirem suas cervejas e ao optarem por este tipo de operação apresentam 
um modelo de negócio especializado em uma parte da cadeia de valor, enquanto terceiriza as outras, mantém custos de transação mais baixos e diminuem em aproximadamente 10 vezes a necessidade de investimento inicial.

\section{GESTÃO DE SUPRIMENTOS E COMPRAS}

Da primeira a terceira etapa, que tratam do processo de compra, monitoramento da entrega e recebimento, ilustradas na figura 1, se origina a gestão de suprimentos e compras (FRANCISCHINI; GURGEL, 2013; SLACK; CHAMBERS; JOHNSTON, 2009). Este processo será demonstrado na Figura 2.

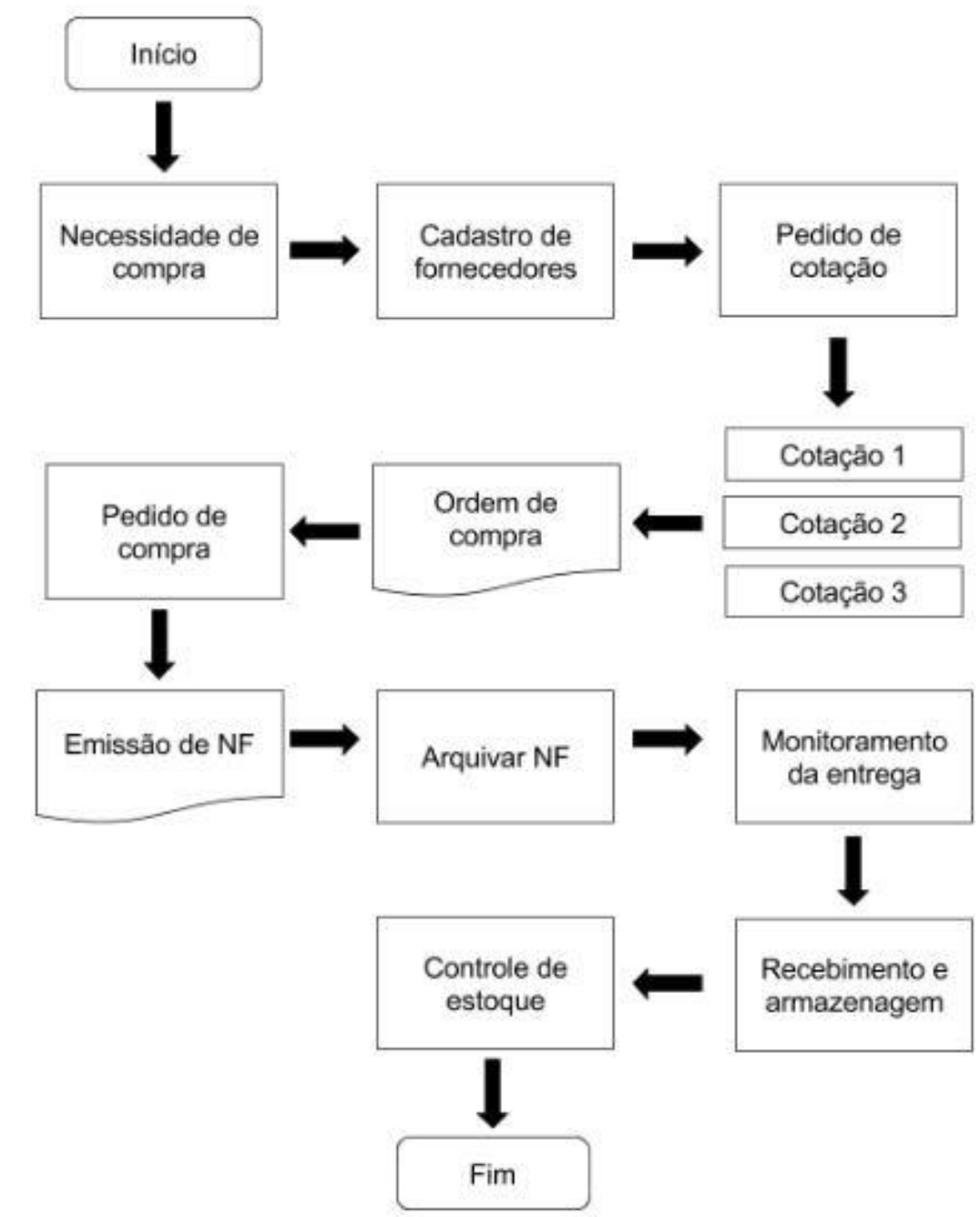

Figura 2 - Fluxograma do processo de compra Fonte - Francischini e Gurgel (2013).

A necessidade de compra, primeira etapa do processo apresentado na Figura 2, é observada ao identificar todo o material necessário para a realização de um ciclo de 
produção que envolva as quatro receitas das cervejas, já descritas anteriormente, que serão comercializadas pela microcervejaria.

As matérias-primas que serão utilizadas na produção da cerveja que será comercializada pela empresa deste Modelo Operacional serão Água, Malte e Lúpulo, seguindo as orientações da lei de pureza alemã, que Morado (2009) explica ser uma lei instituída em 1516, mas que hoje é utilizada pelas microcervejarias para indicar a alta qualidade de seus produtos, fazendo inclusive constar em seus rótulos e materiais de divulgação.

Desta forma, de acordo com a legislação brasileira (BRASIL, 2015) a cerveja produzida nesta microcervejaria será classificada como cerveja especial, já que usará malte de cevada em proporção maior que $75 \%$ em relação ao seu extrato primitivo, como fonte de açúcares.

Tanto a legislação brasileira quanto a literatura específica relacionada ao tema definem características e determinações relacionadas a estes ingredientes. Além dos ingredientes, a embalagem utilizada para o envase da cerveja e os rótulos também possuem especificações que devem ser obedecidas.

A água é um ingrediente muito importante para a cerveja já que corresponde a cerca de $90 \%$ de sua composição total, tendo grande participação na qualidade final do produto (HUGHES, 2016; MORADO, 2009; SENAI, 2014;). De acordo com a legislação brasileira (BRASIL, 2009) a água utilizada para produção deverá ser potável, mesmo que tratada através de substâncias químicas, por processo físico ou outro que lhe assegure as características desejadas para boa qualidade do produto.

O malte de cevada, por possuir um alto teor de amido que durante o processo produtivo será convertido em álcool e gás carbônico pelo levedo, possui também alto teor de enzimas (proteínas específicas) e baixo teor de lipídios o que o torna o cereal mais adequado par a produção de cerveja (HUGHES, 2016; MORADO, 2009; SENAI, 2014).

Os lúpulos são as flores cônicas da planta fêmea de uma trepadeira, que são desidratadas e adicionadas à cerveja para dar amargor, sabor, aroma e para combater as bactérias e diferente do malte (HUGHES, 2016; MORADO, 2009; SENAI, 2014).O lúpulo não altera o teor alcoólico nem o corpo da cerveja, mas confere à bebida o amargor característico da maioria das boas cervejas, além de aromas que variam do herbal ao floral, do frutado ao condimentado, dando personalidade ao produto (HUGHES, 2016; MORADO, 2009; SENAI, 2014). 
O levedo é um fungo microscópico, fundamental na produção da cerveja, que durante o processo de fermentação produz álcool e gás carbônico enquanto consome os açúcares fermentáveis presentes no mosto (HUGHES, 2016; MORADO, 2009).

Com relação à embalagem, Hughes (2016) explica que por poderem ir à geladeira e serem fáceis de transportar, as garrafas são uma das melhores embalagens para cerveja, mas possuem como desvantagem levarem mais tempo para serem limpas e esterilizadas e devem ser escuras, pois o lúpulo reage a luz do sol, podendo assim alterar o sabor do produto.

Os rótulos são definidos pela legislação brasileira (BRASIL, 2009) como toda inscrição, legenda, imagem ou matéria descritiva, gráfica, escrita, impressa, estampada, fixada por encaixe, gravada ou colada, vinculada à embalagem, de forma unitária ou desmembrada, sobre a embalagem da bebida e deve conter nome empresarial e endereço do produtor ou fabricante, do padronizador, do envasilhador ou engarrafador, número do registro do produto no Ministério da Agricultura, Pecuária e Abastecimento, denominação do produto, marca comercial, ingredientes, a expressão: Indústria Brasileira, por extenso ou abreviada, graduação alcoólica, expressa em porcentagem de volume alcoólico, quando bebida alcoólica, - identificação do lote ou da partida, prazo de validade, frase de advertência, conforme estabelecido em legislação específica e conteúdo, expresso na unidade de medida correspondente, de acordo com normas específicas. O CONAR (2008) sugere as frases de advertências para o rótulo: Venda e consumo proibida para menores de 18 anos; Este produto é destinado para adultos; Beba com moderação, dentre outras. A empresa seguirá estas determinações nos rótulos já apresentados no plano de marketing deste Plano Operacional.

A quantidade de suprimentos necessários para um ciclo produtivo está ilustrada na Quadro 1, mas não sem especificações ou separação por produto final, para manter a confidencialidade das receitas.

O número de garrafas, tampinhas e rótulos são correspondentes ao número de produtos produzidos já descritos na Tabela 1 . O número de caixas é referente à $1 / 12$ do número de unidades produzidas. Elas serão utilizadas na etapa de distribuição para embalar as garrafas para o transporte. 


\begin{tabular}{|l|l|}
\hline \multicolumn{1}{|c|}{ Matéria Prima } & \multicolumn{1}{c|}{ Quantidade } \\
\hline Malte & $947,50 \mathrm{Kg}$ \\
\hline Lúpulos & $17,25 \mathrm{Kg}$ \\
\hline Leveduras & $2 \mathrm{~kg}$ \\
\hline Garrafas & 6680 Unidades \\
\hline Tampinhas & 6680 Unidades \\
\hline Rótulos & 6680 Pares \\
\hline Caixas de Estoque & 557 Unidades \\
\hline
\end{tabular}

Quadro 1-Tabela de materiais necessários para um ciclo operacional

Feita a análise de necessidade de compra a próxima etapa é a identificação e cadastro de fornecedores. De acordo com Francischini e Gurgel (2013) este processo deve ser dividido em pesquisa e avaliação de fornecedores potenciais, seleção e cadastro de fornecedores e acompanhamento do desempenho do fornecimento.

Após o processo de pesquisa, para que sejam cadastrados, os fornecedores terão como pré-requisito a comprovação, através de certificações ou histórico, da qualidade da matériaprima fornecida e capacidade de entrega de acordo com a necessidade e prazo exigido pelo ciclo operacional. O objetivo é reduzir ao máximo a necessidade de estoques, já que o modelo de cervejaria cigana parte do ponto de que, da mesma forma que não se possui uma fábrica própria, não há também armazéns destinados a estoque de matéria-prima ou qualquer outro produto.

Depois de selecionar os fornecedores, o acompanhamento do desempenho do fornecimento será feito através dos indicadores cumprimento de prazos, atendimento e cumprimento dos requisitos de qualidade da matéria-prima. É de relevante importância o estreitamento de relação com os fornecedores, o que possibilita a facilidade de troca de informações entre setores, resolução de problemas com facilidade, maior transparência nas negociações, segurança quanto à estabilidade de preços, melhores negociações e colaboração para novos projetos (FRANCISCHINI; GURGEL, 2013; SLACK; CHAMBERS; JOHNSTON, 2009).

Feito o cadastro, a etapa seguinte se trata da realização das cotações. De acordo com Francischini e Gurgel (2013) nesta etapa, pela primeira vez, o preço é fator importante na tomada de decisão relacionada à compra, porém não pode ser o único critério de escolha, pois 
também deve se levar em consideração critérios classificadores e qualificadores, que são descritos no trecho a seguir:

Critérios qualificadores, como próprio nome diz, são requisitos exigidos dos fornecedores que os qualificam como potenciais fornecedores. Os critérios qualificadores são estabelecidos pela empresa compradora e devem abranger aspectos críticos que estejam de acordo com seus objetivos estratégicos e que garantam a qualidade e confiabilidade dos prazos de entrega dos produtos adquiridos (FRANCISCHINI; GURGEL, 2013, p. 78)

[...] os critérios classificadores não possuem requisitos mínimos a serem atendidos pelos fornecedores em potencial. Eventualmente, os compradores podem estabelecer um requisito objetivo a ser atingido pelos fornecedores em certo período de tempo (FRANCISCHINI; GURGEL, 2013, p. 79).

O modelo operacional proposto adota como critério qualificador ou requisito mínimo a conformidade legal do fornecedor, o sistema de garantia de qualidade do material fornecido, a capacidade de adequação da entrega com o ciclo produtivo da empresa e o histórico de fornecimento adequado ao mercado. Os critérios classificadores serão o preço e a flexibilidade das condições e prazos de pagamento. Para realizar as cotações a empresa terá um formulário próprio, contendo as informações necessárias para a tomada de decisão de compra, que será encaminhada por e-mail para os fornecedores.

Francischini e Gurgel (2013) acrescentam que a negociação faz parte do processo de compra, momento em que ocorrem as alterações, adequações relacionadas à quantidade, preço e serviços associados, para satisfação de ambas as partes.

Para cada pedido será feito um mínimo de três cotações para maior segurança no processo e facilidade de troca caso haja algum imprevisto com um dos fornecedores. $\mathrm{O}$ cabeçalho do formulário é representado na Figura 3:

\begin{tabular}{|l|l|l|l|l|}
\hline Fornecedor & Prazo pagamento & Prazo entrega & Valor frete & Preço do pedido \\
\hline & & & & \\
\hline Produto & Quantidade & Preço unitário & Preço total \\
\hline & & & \\
\hline
\end{tabular}

Figura 3 - Formulário para cotações

A próxima etapa a ser realizada é o pedido de compra que é antecedido pelo preenchimento adequado da ordem de compra, ilustrada na Figura 4, que para Francischini e Gurgel (2013) se trata de um documento de suma importância para facilitar o gerenciamento 
do processo como um todo, pois nela estará registrada os valores do pedido, data de realização do pedido, a quantidade solicitada de cada matéria-prima e fornecedor que realizará a entrega.

Neste modelo operacional, sempre que houver necessidade de compra, o responsável pelo setor irá preencher uma requisição, que deve ser aprovada pelo departamento financeiro. Nesta requisição haverá a descrição da matéria prima solicitada, a quantidade necessária, preço e fornecedor.

\begin{tabular}{|c|c|c|c|c|c|}
\hline \multicolumn{4}{|c|}{ Departamento: } & \multicolumn{2}{|l|}{ OC n ${ }^{\circ}:$} \\
\hline \multicolumn{2}{|c|}{ Fornecedor: } & \multicolumn{2}{|c|}{ Pedido:_L___ } & \multicolumn{2}{|c|}{ Previsão entrega:________ } \\
\hline Código & Descrição & & & Quantidade & Preço \\
\hline \multicolumn{6}{|c|}{ Forma e datas de pagamento: } \\
\hline \multicolumn{3}{|c|}{ Responsável OC: } & \multicolumn{3}{|c|}{ Autorização Financeiro: } \\
\hline
\end{tabular}

Figura 4 - Formulário para ordem de compra

No processo de acompanhamento da entrega e do recebimento é importante ressaltar que atrasos podem comprometer o ciclo produtivo como um todo e devem ser evitados por parte dos fornecedores e caso algum imprevisto ocorra, o monitoramento deve trabalhar para reduzir os impactos deste problema.

A função básica do recebimento de materiais é assegurar que o produto entregue esteja em conformidade com as especificações constantes no pedido de compra (FRANCISCHINI; GURGEL, 2013). Ao receber as entregas o colaborador fará a conferência da nota fiscal em relação ao material entregue. Caso esteja tudo de acordo, ele fará o encaminhamento do produto para o departamento responsável. Caso haja algum problema, ele deverá entrar em contato com o responsável pela compra para que ele solucione.

Como já explicado, a ausência de armazéns de uma microcervejaria cigana torna estratégico neste modelo operacional trabalhar com o menor número de estoque possível e por isso as compras serão realizadas por ciclo de produção, que começará no momento em que as matérias-primas forem entregues pelos fornecedores, para que sejam quase que na totalidade utilizadas no mesmo dia da entrega. 
De acordo com Francischini e Gurgel (2013) é fundamental otimizar os processos relacionados aos estoques para que se reduza a necessidade de capital, adequando as compras de matéria-prima à produção, em busca de alcançar o ideal de desempenho de uma empresa, que é manter o estoque zero.

Isso fará com que o estoque seja basicamente composto por mercadorias em preparação para serem utilizadas no processo produtivo. Haverá também embalagens e lotes de materiais que serão superiores a quantidade necessária para um ciclo produtivo. Assim estas sobras também serão estocadas seguindo as recomendações do fornecedor.

A legislação brasileira (BRASIL, 2000) deixa claro que a matéria prima usada no processo produtivo deve ser armazenada de forma que reduza ao mínimo as chances de danos e deteriorações e haja total garantia de proteção contra contaminações.

\section{GESTÃO DAS ETAPAS TERCEIRIZADAS}

Terceirização é uma escolha estratégica, em que uma empresa passa para outra a responsabilidade de execução de uma ou mais atividades com o objetivo de reduzir custos e enxugamento da estrutura da organização para focar as ações da empresa no que é de fato essencial para sua sobrevivência no mercado (AMATO NETO, 1995; ARAUJO, 2012; HITT; IRELAND; HOSKISSON, 2008).

Chaves (2017) explica que a terceirização de etapas da produção no mercado de cervejas artesanais tem se tornado cada vez mais comum, se estabelecendo como uma forma de organização neste mercado e é conhecida como cervejaria por contrato ou cervejaria cigana.

O objetivo da empresa deste Plano Operacional ao adotar esta estratégia é a redução de custos fixos e a redução da necessidade de um grande volume de investimento inicial para o início das operações. Desta forma, a empresa dispensa a necessidade de uma planta de fábrica, da manutenção da mesma e de recursos humanos para sua operacionalização.

A seleção da empresa parceira que realizará as etapas terceirizadas deve ser considerada como um fator preponderante para o sucesso da microcervejaria cigana. $\mathrm{O}$ processo de seleção da empresa parceira deve ser feito da mesma maneira que a seleção de fornecedores, já descrita neste artigo. Devem ser levados em consideração tanto critérios classificadores, como também os qualificadores. Luna (2006) apresenta uma pesquisa detalhada quanto à seleção de empresas parceiras com enfoque nas operações logísticas. 
As etapas terceirizadas estão demarcadas na Figura 1. De qualquer forma os processos destas etapas serão descritos a seguir neste Modelo Operacional, para o acompanhamento dos procedimentos e para garantia da qualidade do produto final.

Morado (2009) explica que a preparação dos equipamentos tem como função principal a sanitização dos mesmos, o que evitará riscos de contaminação e perdas de lotes de produção.

A moagem é o processo onde se inicia a transformação do malte para conversão em cerveja e deve ser realizado pouco antes do início da mostura para quebrar o grão e expor o amido contido no seu interior, observando sempre que a casca deve ser preservada e não transformada em pó, pois ela será útil no processo de filtragem (HUGHES, 2016; MORADO, 2009; SENAI, 2014).

A mostura consiste em adicionar água ao malte moído na panela de brassagem, submetendo-o a diferentes temperaturas por um tempo pré-determinado pela receita escolhida para obter uma solução adocicada, denominada mosto (HUGHES, 2016; MORADO, 2009; SENAI, 2014).

$\mathrm{Na}$ etapa de filtração do mosto se faz a separação do mosto líquido do bagaço de malte, que pode ser feito em uma tina de clarificação, usando um fundo falso (espécie de peneira) separando as cascas do malte, que são usadas também como filtros, enquanto é adicionada mais água para extrair e separar por completo todo o mosto líquido que é transferido para o processo de fervura (HUGHES, 2016; MORADO, 2009; SENAI, 2014).

A etapa posterior a da filtração do mosto é a da fervura, momento em que são adicionados os lúpulos, ocorre à esterilização e estabilização do mosto e são eliminados os aromas indesejados (HUGHES, 2016; MORADO, 2009; SENAI, 2014).

A etapa de resfriamento se inicia ao fim da fervura, onde as proteínas contidas no mosto se aglutinam formando o chamado trub, que deve ser separado e descartado para que a cerveja tenha estabilidade no brilho e sabor mais suave, antes de passar pelo processo de diminuição de temperatura para adição das leveduras, o que deve ocorrer da forma mais rápida possível para se evitar contaminações (HUGHES, 2016; MORADO, 2009; SENAI, 2014).

Após resfriado, o mosto será transferido para tanques onde ocorrerão as etapas de fermentação, que se trata da transformação dos açúcares contidos no mosto em dióxido de carbono e etanol, através da ação das leveduras em temperatura controlada, e a maturação, que é o tempo em que o mosto fica em descanso em temperatura inferior ao da fermentação, 
onde ocorrem reações físico-químicas responsáveis por dar à cerveja um melhor visual, aroma e sabor (HUGHES, 2016; MORADO, 2009; SENAI, 2014).

A filtração é a etapa onde se dá um acabamento brilhante à cerveja, separando todos os possíveis resíduos e leveduras ainda presentes no produto (MORADO, 2009; SENAI, 2014).

Após a cerveja filtrada se inicia a etapa da carbonatação, que tem como objetivo corrigir, caso ao fim da maturação a cerveja não apresente a quantidade de dióxido de carbono desejada, através da injeção de gás carbônico (HUGHES, 2016; MORADO, 2009; SENAI, 2014).

A etapa do envase é um momento que exige bastante atenção com relação à limpeza e sanitização para se evitar contaminações quando for retirar a cerveja dos tanques para transferi-la para as garrafas (HUGHES, 2016; MORADO, 2009; SENAI, 2014).

A pasteurização, de acordo com Oetterer, Regitano-D’Arce e Spoto (2006) pode ser através de trocadores de calor, onde a cerveja é rapidamente aquecida até $75^{\circ} \mathrm{C}$ e depois resfriada, antes de passar pelo processo de envase ou através de aspersão de água quente, elevando a temperatura até $65^{\circ} \mathrm{C}$, mantendo por cerca de 20 minutos, para depois ser resfriada com o objetivo de destruir microrganismos ainda presentes na cerveja, para que haja estabilidade biológica no produto.

Após serem pasteurizadas, as garrafas serão colocadas em caixas de papelão para doze unidades. 50\% das garrafas serão colocadas em caixas com apenas uma receita e os outros $50 \%$ serão embalados em caixas com as quatro receitas produzidas divididas igualmente em três unidades de cada uma. Esta forma de separação facilitará a comercialização diversificada e o atendimento aos varejistas que poderão optar por comprar uma receita ou todas ao mesmo tempo, mas em menor quantidade.

\section{GESTÃO DA DISTRIBUIÇÃO FÍSICA}

Ainda seguindo o objetivo estratégico de redução de estoques ao menor número possível, como já apresentado no processo de compra de matéria-prima, este Modelo Operacional trabalha com a entrega dos produtos no momento que se encerra o ciclo produtivo. Com o objetivo de redução de custos, a entrega será feita diretamente aos varejistas pela própria microcervejaria, dispensando assim o uso de distribuidores, utilizando uma rede de distribuição de apenas três níveis apresentada na figura 5. 


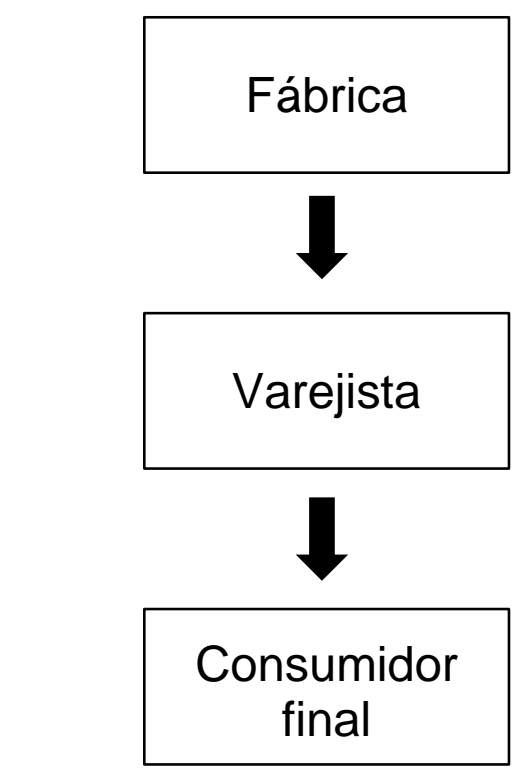

Figura 5 - Rede de distribuição de três níveis

A realização do transporte dos produtos será feito através de caminhão terceirizado. Esta escolha é justificada pela explicação de Russo (2013) que aponta o modal rodoviário como o mais utilizado no país por possuir maior disponibilidade de vias de acesso, possibilitar o serviço porta a porta, possibilitar rapidez no embarque e nas partidas, ser recomendável para curtas e médias distâncias, ter funcionamento simples e rápido e exigir embalagens de menor custo.

Há uma pesquisa voltada exclusivamente para os fatores críticos relacionados a distribuição física, desde a seleção de prestadores do serviço aos cuidados específicos durante as operações. Morelli e Simon (2012) apresentam estudos relevantes para maior aprofundamento no assunto e adaptação deste modelo de Plano Operacional para outros formatos de organização.

\section{CONSIDERAÇÕES FINAIS}

Este artigo abre espaço para que o modelo de negócio conhecido como cervejaria cigana receba mais atenção do meio acadêmico, no sentido da construção de novos estudos relacionados a este modo de atuação de microcervejarias. Muito ainda pode ser desenvolvido quanto a este tema, no que tange o mercado consumidor, planejamento financeiro, estratégias mercadológicas, dentre outros.

Neste artigo o intuito foi propor um Modelo Operacional que possibilite que administradores e empreendedores tenham um direcionamento para suas atividades, baseados 
em teorias altamente difundidas da administração, mas que foram apresentadas de forma aplicável a este modelo de negócio específico, o que acarreta diminuição de riscos e melhora na produtividade destas empresas do setor cervejeiro, que tem crescido muito no Brasil e que, pelas previsões já apresentadas, crescerá ainda mais, gerando desenvolvimento econômico na região em que atuam.

Este Modelo Operacional propõe, de forma clara, métodos e processos que devem ser aplicados por cervejarias ciganas em busca de competitividade e sobrevivência no mercado. Por ser flexível, ele se adapta a volumes de produção maiores ou menores aos utilizados no artigo, o que o torna mais eficiente e aplicável para um maior número de interessados.

Desta forma, um administrador ou empreendedor que estiver com um plano de negócio, ou até mesmo já em operação com uma cervejaria cigana, encontrará informações relevantes neste artigo para melhora da produtividade e qualidade da empresa que atua ou atuará.

\title{
OPERATIONAL MODEL FOR CONTRACT BREWERIES
}

\begin{abstract}
This paper proposes an operational model for entrepreneurs and craft beer market managers. Abisiness model that has become very common in this growing contract brewer market. In that model, brewers outsource their production to decrease costs and concentrate efforts in other points of the supply chain. Through the proposed model of a microbrewery, this article carry out systematically how the operation of a competitive and itinerant brewery should be. Several management theories guide planning and execution of actions, from the identification of the need to raw materials acquisitions to retailer's distribution. Moreover, this papers presents a brewery regulation in Brazil, Brazilian and worldwide itinerant brewer's history and economic panorama about consumer market in the last years.
\end{abstract}

Keywords: Microbrewery. Production management. Outsourcing. Operational model.

\section{REFERÊNCIAS}

AMATO NETO, J. Reestruturação industrial, terceirização e redes de subcontratação. Revista de Administração de Empresas, São Paulo, v. 35, n. 2, p. 33-42, mar./abr. 1995. Disponível em: <http://www.scielo.br/pdf/rae/v35n2/a06v35n2.pdf>. Acesso em: 07 jul. 2017.

ANDRADE, M. M. Introdução à metodologia do trabalho científico: elaboração de trabalhos na graduação. São Paulo: Atlas, 2010. 
ARAUJO, L. C. G. Organização, sistemas e métodos e as tecnologias da gestão organizacional. São Paulo: Atlas, 2012.

ASSOCIAÇÃO BRASILEIRA DA INDÚSTRIADA CERVEJA (CERVBRASIL). Dados do setor. São Paulo, [2015]. Disponível em: <http://www.cervbrasil.org.br/paginas/ index.php? page $=$ dados-do-setor $>$. Acesso em: 18 mar. 2017.

BRASIL. Decreto $n^{\circ}$ 6.871, de 4 de junho de 2009. Diário Oficial [da] República Federativa do Brasil, Brasília, DF, 05 jun. 2009. Seção 1, p. 20. Disponível em: <http://www.planalto.gov.br/ccivil_03/_ato2007-2010/2009/decreto/d6871.htm>. Acesso em: 18 mar. 2017.

BRASIL. Ministério da Agricultura, Pecuária e Abastecimento. Secretaria de Defesa Agropecuária. Instrução Normativa ${ }^{\circ}$ 5, de 31 de março de 2000. Diário Oficial [da] República Federativa do Brasil, Brasília, DF, 05 abr. 2000. Seção 1, p. 10. Disponível em: $<$ http://sistemasweb.agricultura.gov.br/sislegis/action/detalhaAto.do?method=consultarLegisl acaoFederal>. Acesso em: 4 abr. 2017.

CHAVES, R. L. P. Reinventing a business model: how contract breweries became a permanent form of organizing. 2016. 71 f. Dissertação (Mestrado Executivo em Gestão Empresarial da Escola Brasileira de Administração Pública e de Empresas da Fundação Getúlio Vargas - FGV/EBAPE) - Fundação Getúlio Vargas, Rio de Janeiro, 2016. Disponível em: 〈https://bibliotecadigital.fgv.br/dspace/handle/10438/17610>. Acesso em: 01 abr. 2017.

CONAR. Código Brasileiro de Autorregulamentação Publicitária Código e Anexos CONAR. São Paulo, Resolução No 02/08 Ref. anexo "P”. 2008. Disponível em <http://www.conar.org.br/>. Acesso em 31 mar. 2017.

CONSELHO NACIONAL DE AUTORREGULAMENTAÇÃO PUBLICITÁRIA (CONAR). Código Brasileiro de Autorregulamentação Publicitária: código e anexos - CONAR. São Paulo, 2008. Disponível em <http://www.conar.org.br/>. Acesso em 31 mar. 2017.

DELGADO, Y. L. Plano de negócio para microcervejaria artesanal. Porto Alegre: UFRGS, 2016.

DORNELAS, J. C. A. Empreendedorismo: transformando ideias em negócios. São Paulo: Elsevier, 2008.

FRANCISCHINI, P. G; GURGEL, F. A. Administração de materiais e do patrimônio. São Paulo: Cengage Learnig, 2013.

HISRICH, R. D; PETERS, M. P; SHEPHERD D. A. Empreendedorismo. Porto Alegre: Bookman, 2009. 
HITT. M. A; IRELAND, R. D; HOSKISSON, R. E. Administração estratégica: competitividade e globalização. São Paulo: Cengage Learning, 2011.

HUGHES, G. Cerveja feita em casa. São Paulo: Publifolha, 2016.

LUNA, M. M. M. O processo de terceirização das atividades logísticas. In: SIMPÓSIO DE ADMINISTRAÇÃO DA PRODUÇÃO, LOGÍSTICA E OPERAÇÕES INTERNACIONAIS - SIMPOI, 9., 2006, São Paulo. Anais... São Paulo: FVG-EAESP, 2006.

MORADO, R. Larousse da cerveja. São Paulo: Larousse, 2009.

MORELLI, D.; SIMON, A. T. Terceirização de sistemas de distribuição física: um estudo de caso em um operador logístico. In: ENCONTRO NACIONAL DE ENGENHARIA DE PRODUÇÃO, 32., 2012, Bento Gonçalves. Anais... Bento Gonçalves: Enegep, 2012.

OETTERER, M; REGITANO-D’ARCE, M. A. B; SPOTO, M.H.F. Fundamentos de ciência e tecnologia de alimentos. São Paulo: Manole, 2006.

ROSA, C. A. Como elaborar um plano de negócios. Brasília: SEBRAE, 2013.

RUSSO, C. P. Armazenagem, controle e distribuição. Curitiba: InterSaberes, 2013.

SEBRAE. Microcervejarias. [S.1.], [20--]. Disponível em: <http://www.bibliotecas.sebrae. com.br/chronus/ARQUIVOS_CHRONUS/bds/bds.nsf/8818d2954be64fcda8628defef1f70f8/\$ File/7503.pdf>. Acesso em: 18 mar. 2017.

SENAI. Tecnologia cervejeira. Rio de Janeiro: SENAI, 2014.

SLACK, N; CHAMBERS, S; JOHNSTON, R. Administração da produção. São Paulo: Atlas, 2009.

SZWARCFITER, C; DALCOL, P. R. T. Economias de Escala e de Escopo: desmistificando alguns aspectos da transição. Produção, Belo Horizonte, v. 17, n. 2, p.117-129, nov. 1997. Disponível em: 〈http://www.scielo.br/pdf/prod/v7n2/v7n2a01〉. Acesso em: 15 jul. 2017.

\section{DADOS DOS AUTORES:}

\section{Raphael Athos dos Santos}

E-mail: raphaelathos@ outlook.com

Tecnológo em Processos Gerenciais pelo Instituto Federal de Educação, Ciência e Tecnologia de Minas Gerais - Campus Sabará. 


\section{Luciana Emirena dos Santos Carneiro}

Lattes: http://lattes.cnpq.br/5770909602565313

E-mail: luciana.emirena@ifmg.edu.br

Doutoranda em Ciência da Informação em Gestão da Informação e do Conhecimento, pela Universidade Federal de Minas Gerais. Mestre em Ciência da Informação pela UFMG (2012). Especialista em Gestão da Informação pela UFMG (2010). Graduada em Administração pelo Centro Universitário Newton Paiva

\section{Lucas Maia dos Santos}

Lattes: http://lattes.cnpq.br/6936984179200806

E-mail: lucas.maia@ifmg.edu.br

Doutor em Administração pela Universidade Federal de Minas Gerais (2015). Mestre em Administração pela UFMG (2011). Graduado em Administração pela Universidade Federal de Viçosa (2010). Atualmente é professor efetivo do Instituto Federal de Minas Gerais Campus Sabará. 